\title{
DE MUJERES Y DIOSAS
}

\author{
Elena Menéndez Requeno \\ Universitat Politècnica de València. Programa de Doctorado en Arte: Producción e Investigación
}

\section{Resumen}

Este artículo está basado en el estudio de la representación y significado de la divinidad femenina en el arte feminista, una imagen surgida en el feminismo de segunda ola estadounidense en las décadas de los sesenta y setenta del siglo pasado. En las siguientes páginas trataremos de mostrar cómo esta imagen se convirtió en una metáfora para los diferentes requerimientos de varias artistas relacionadas con este movimiento, tales como la conexión entre la mujer y la naturaleza, su preocupación sobre la sexualidad femenina, sobre cómo es representado el cuerpo de la mujer en el arte, una crítica contra las religiones patriarcales, una reivindicación de la Historia de las Mujeres y una reivindicación socio-cultural, de modo que la representación de la Gran Diosa en el arte de este movimiento es el resultado de todas estas peticiones ya citadas, así como una forma de canalizar todas ellas dentro del arte feminista.

Palabras-clave: DIVINIDAD FEMENINA; GRAN DIOSA; ARTE FEMINISTA; FEMINISMO

\section{OF WOMEN AND GODDESSES}

\section{Abstract}

This article is based on the study of female divinity in feminist art, a common icon during the second wave of the feminist movement in USA in the late 1960s and throughout the 1970s. In the following pages we'll tend to show how this image became a metaphor for the different vindications of many women artist who were related to this movement, such as: the connection between woman and nature, their concern about women's sexuality, about how women's bodies are represented in Art, a criticism about patriarchal religions and beliefs, the vindication of the History of Women and a socio-cultural conception; so in the end, the Great Goddess representation in the art of this movement means all the claims we've already named and a way to focus all of them in feminist art.

\section{Keywords: FEMALE DIVINITY; GREAT GODDESS; FEMINIST ART; FEMI- NISM}

\footnotetext{
Menéndez Requeno, Elena. 2017 . "De mujeres y Diosas". AusArt 5 (1): 129-140 DOI: 10.1387/ausart.17785
}

\section{AUSART}


"El significado más simple y básico del símbolo de la Diosa es el reconocimiento de la legitimidad del poder de la mujer como una fuerza benéfica e independiente".

Carol P. Christ

La divinidad femenina es una temática presente y recurrente en el arte de numerosas artistas ligadas al movimiento feminista de segunda ola y cuya repercusión ha llegado hasta nuestros días. A pesar de ello estas representaciones se han convertido en unas grandes desconocidas dentro del arte del movimiento, así como del arte en general, un hecho que, sumado a la gran escasez de información y material de estudio que encontramos sobre ellas en nuestro país, resultó ser el motivo principal por el que se decidió investigar acerca de la representación artística de la Gran Diosa en el feminismo.

Esta complicada labor de rescatar información sobre el tema reside en el desprestigio que sufrieron estas manifestaciones artísticas, cuyo carácter religioso, místico y mágico, fue vinculado con religiones paganas y cultos primitivos en su sentido más peyorativo, denotándolas como simples, falsas y extravagantes. Este hecho es en parte producto de la concepción que persiste en nuestra sociedad sobre la temática de la magia o sobre los cultos primitivos, los cuales han sido impregnados a lo largo del tiempo, y en nuestra mente colectiva, de un tinte de desprecio, al entenderlos como supersticiones antiguas y siendo obviados por su relación con conocimientos o sociedades menos avanzadas. Por otro lado se encuentra el hecho de que estas representaciones de las que hablamos se desarrollan de mano del movimiento feminista, sujeto a polémicas y constantes críticas desde sus inicios, por lo que no es de extrañar que, en estas circunstancias, las manifestaciones artísticas ligadas a la divinidad femenina pasaran prácticamente desapercibidas.

El presente artículo, de este modo, busca ser una toma de contacto con estas representaciones artísticas dentro del movimiento feminista de segunda ola y exponer que, tomada no solo como mera imagen religiosa o mágica, sino que observándola también desde un prisma social, cultural y político, la Gran Diosa del feminismo supuso una suerte de metáfora que aunaba las diversas reivindicaciones del movimiento de liberación de la mujer en un momento y lugar específico: los Estados Unidos de América a partir de la década de los años sesenta del siglo pasado. Un proyecto que se llevó a cabo a través del estudio de diferentes obras, de la búsqueda de conexiones existentes entre las diferentes artistas, de notas autobiográficas y del análisis de sus obras, así como también de publicaciones y artículos de la época y de actualidad 
que denotan cómo estas imágenes se convirtieron en una suerte de metáfora que englobase los ideales de la lucha feminista en una época convulsa y que resultó el germen de numerosos cambios sociales. Para ello, se plantearán siete bloques fundamentales en los que la imagen de la divinidad femenina se verá fragmentada, tratándola en cada uno de ellos como imagen que refleja una serie de reivindicaciones del colectivo, a saber: una revisión del cuerpo de la mujer como cuerpo natural, una reivindicación de la sexualidad femenina, una conquista por parte de las mujeres de sus propios cuerpos en la representación artística, la revalorización del papel de la mujer en la Historia, una crítica a la violencia misógina, una crítica a la institución religiosa (principalmente la religión cristiana), así como una revisión cultural y política, desarrollando cada uno de dichos apartados a lo largo del escrito y ejemplificando las teorías que nos llevan a identificarlos.

Como mencionábamos anteriormente, el momento y lugar en el que este tipo de arte comienza a hacerse visible es imprescindible para entender su desarrollo. Los años sesenta en los Estados Unidos de América plantearon un clima social hostil. El fantasma de la IIGM, así como los diferentes conflictos que se abrían paso en este momento y lugar, llamaban a varios grupos sociales a la necesidad de buscar alternativas para un clima social que les creaba rechazo. Esta necesidad de cambio y sensación de repulsa del propio pueblo hacia los valores de su sociedad dio como fruto la aparición de numerosos movimientos, muchos de ellos tan conocidos como el movimiento hippie, el movimiento ecológico o el auge de la segunda ola del feminismo. Estos movimientos citados, aunque muy diferentes a primera vista, se encuentran estrechamente relacionados y presentan ideas comunes entre sí, ya que todos se basaban en la revalorización de grupos marginados que la sociedad había relegado o incluso excluido de su propio sistema.

El crecimiento del movimiento ecológico, así como del movimiento hippie se basa en el rechazo de un modelo social, y en respuesta a ello, la puesta en valor de aquellos modelos culturales alternativos, que en aquel momento resultaron ser aquellos grupos sociales más vilipendiados en la sociedad estadounidense: los colectivos nativos americanos, quienes aceptaban la naturaleza como un ente más en su vida, así como se entendían de diferente modo las jerarquías y relaciones entre las personas que comprendían un mismo grupo.

En esta búsqueda de modelos alternativos por parte de los diferentes grupos emergentes, los hallazgos que se dieron dentro del feminismo, con la aparición de teóricas e investigadoras, supondrían una herramienta muy valiosa 
para este proceso de revalorización de la mujer. Uno de los más importantes, en cuanto al tema que nos ocupa, fueron las aportaciones de la arqueóloga Lituano-Estadounidense Marija Gimbutas, en quien nos centraremos en mayor medida en este artículo, ya que su inspiración para el desarrollo del arte que estamos tratando es clave. Marija Gimbutas aseguraba haber encontrado vestigios del más antiguo culto que se conoce, emplazado en el Neolítico en lo que ella denominaría como la Vieja Europa.

Estas investigaciones sacaban a la luz vestigios de una sociedad en la que las jerarquías no se basarían en la condición de género sino que se trataría de una sociedad que procuraría el bienestar de todos sus miembros de forma colaborativa y exenta de violencia, una sociedad en la que la que tanto hombres como mujeres se encontrasen en posiciones de poder y valía, unas teorías que supusieron un hilo del que tirar para numerosas artistas feministas, que dio como resultado que muchas de ellas exploraran acerca de mitos en los que la mujer se consideraba liberada de estereotipos y restricciones.

No obstante estas teorías resultaron polémicas en una sociedad con claro carácter religioso, en la que la idea de una divinidad femenina anterior a todo y un modelo de sociedad matrilineal, se entendía como algo improbable, siendo objeto de burlas y rechazada. A pesar de ello, la utilización de estos hallazgos en el arte continuó dando como fruto numerosas obras así como inspiró a muchas otras teóricas a continuar en la búsqueda de civilizaciones cuyas costumbres demostraran que una sociedad igualitaria es posible.

\section{EL VÍNCULO CON LA NATURALEZA Y LA SEXUALIDAD}

La representación de la Diosa como relación con la parte más natural de la mujer es hablar de una de las apropiaciones que se realizó por parte del denominado feminismo de la esencia, el cual reivindicaba el papel del cuerpo femenino relacionándolo con el entorno natural frente a la racionalidad que representaba el varón. La relación de la mujer con la naturaleza era un imperativo patriarcal con el fin de menospreciarlas y apoyar su tesis de su minusvalía frente al hombre en los temas de importancia, relacionándola con la animalidad y lo primitivo por su condición biológica de "dadora de vida". Por sus ciclos periódicos la mujer era tachada de ser natural y, por tanto, una persona tempe- 
ramental, desordenada, cambiante o desconcertante como lo es la naturaleza. El feminismo de la esencia se centró en apoyar esta imagen y la hizo suya, asumiendo ese papel natural de la mujer y dignificándolo.

La imagen de la divinidad apoya estas manifestaciones ya que nos encontramos una figura femenina que se confunde con lo animal, como veremos a continuación con el ejemplo del pájaro, fusionándose con este y poniendo de manifiesto esa animalidad inherente en la mujer.

Muchas han sido las artistas que lo han representado, desde Mary Beth Edelson con sus fotografías intervenidas, la película Dyketactics! (1974) de Barbara Hammer o la instalación The Dinner Party (1974-1979) de Judy Chicago, en las que se ve la estrecha relación del cuerpo de la mujer en el entorno natural, así como la relación de la naturaleza con la sexualidad femenina o una necesidad de naturalizar la sexualidad.

Esta conexión con la naturaleza trae consigo la necesidad de experimentación con el cuerpo de la mujer desnudo, natural, lo que pone en tela de juicio los tópicos sobre la desnudez del cuerpo y sobre la sexualidad.

Al mismo modo que la divinidad relaciona el cuerpo femenino con un espacio natural, presenta una oportunidad de representar el cuerpo de la mujer en su totalidad, o sus genitales de un modo más específico y explícito, más allá de las censuras que han impedido su visibilidad en los diferentes periodos históricos.

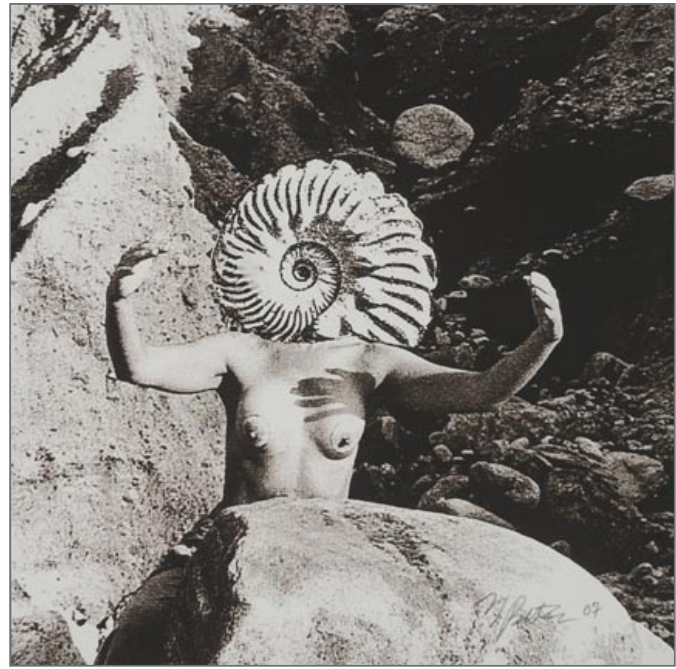

1 Goddess Head, Mary Beth Edelson. 1975

Desde los albores de la humanidad, los genitales femeninos han generado gran expectación debido a la capacidad de engendrar que disponía el cuerpo de la mujer. Un ejemplo cercano a nosotros es la representación de varias vulvas en la cueva de Tito Bustillo en Asturias, aunque es solo un ejemplo de las múltiples manifestaciones que denotan la fascinación que los órganos reproductores femeninos han tenido en la Historia de la Humanidad. 
Así mismo son conocidas por todos las manifestaciones de las mal denominadas "Venus" calificadas de este modo por la relación que se les otorgó con la divinidad romana del amor y la sexualidad, sin embargo, la relación entre estas figuras y antiguas divinidades fue advertida por Marija Gimbutas, quien cuestionaba estas primeras explicaciones dadas a las estatuillas, tachándolas de erróneas.

Las ideas de la arqueóloga distaban de las de muchos arqueólogos y estudiosos, Marija Gimbutas planteaba la idea de que estas representaciones aludían a antiguas divinidades como la Diosa Pájaro, una afirmación que suponía que estas estatuillas representaban uno de los cultos más antiguos del mundo, el culto a una diosa ancestral, expresando en mayor medida la relación de la mujer con la divinidad, así como la existencia de posibles cultos primitivos hacia deidades femeninas.

Del mismo modo sus investigaciones explican cómo las teorías cosmogónicas de los antiguos pueblos europeos se basan en el agua y en la figura de un ave. El agua se veía como elemento primordial, y numerosas manifestaciones artísticas plasmaban el origen del mundo a través de un huevo, dentro del cual residía la vida. Esta idea de huevo también era visible a través de esculturas, en las que se representaba la idea de un pájaro antropomorfo, mostrando la idea de huevo en el propio cuerpo del animal, así como también eran claras evidencias de una estrecha relación entre los mitos de la creación del mundo y la capacidad de concepción de la mujer.

En el neolítico, este mito aparece representado a través de las figurillas denominadas esteatopigias, nombradas de este modo por la gran concentración de grasa que representaban en sus nalgas, recordando a mujeres de tribus africanas como las hotentotes, una interpretación que Marija Gimbutas (1984, 121) califica como equivocada. Para ella estas figurillas son el resultado de la abstracción de las formas de la Diosa Pájaro, cuyas extremidades y cabeza se esquematizan aproximándose a la morfología del ave, conservando en su vientre la imagen del huevo.

"Las mujeres hotentotes no tienen lugar en el arte de la Vieja Europa y es erróneo y engañoso describir las figurillas neolíticas y calcolíticas como esteatopigias. El híbrido de mujer y pájaro proporciona a las figuras de una dignidad mayor, la dignidad de lo sobrenatural. Y es desafortunado que se asociara este término con las figurillas neolíticas" 
Esta relación entre las figuras prehistóricas y el culto a la diosa pájaro también lo recoge Sigfried Giedion en su libro El presente eterno: Los comienzos del arte (1964), donde expone claros ejemplos de la proximidad formal entre ave y mujer, como es el caso de las figurillas encontradas en Mézine (Ucrania), apoyando la existencia de algún tipo de "Magna Mater" primitiva

Sin embargo, este nexo animal no se cerraría a la manifestaciones relacionadas con las diversas aves, sino que se conectaría con diferentes animales y continuarían dándose en las manifestaciones posteriores de las diversas culturas que irían apareciendo con el paso de los años en las diferentes sociedades que poblaron la actual Europa, así como se extenderían y enriquecerían en el continente americano.

Estas representaciones fueron tomadas por el colectivo feminista para reivindicar su propio cuerpo, su visibilidad y una imagen más natural de un cuerpo sexual, amparándose en estas manifestaciones prueban la existencia de una sociedad diferente en el que la represión sexual femenina era inexistente, en la que se aboga por la eliminación de los diferentes prejuicios y tabús a los que ha estado sujeto el cuerpo de la mujer, permitiéndole el autoconocimiento, exploración y goce de su propio cuerpo y su sexualidad.

\section{UnA CONQUiSTA DEL CUERPO FEMENINO Y ERRADICACIÓN DE LA VIOLENCIA}

De este mismo modo y tirando del hilo de la sexualidad y su representación también se abre el tema de la representación del cuerpo de la mujer en el arte, en el que a lo largo de la Historia las representaciones del cuerpo femenino han sido realizadas por parte de artistas (principalmente varones) bajo un una serie de pautas. El cuerpo femenino era representado desnudo y completamente estereotipado, fijo dentro de parámetros de belleza, representado como idealizado, como vulnerable, como una herramienta que focalizaba las necesidades del artista.

Estas manifestaciones han continuado hasta nuestros días cada vez de forma más exacerbada, construyendo en la actualidad unos ideales de cuerpo enfermizos e imposibles de alcanzar, una conducta que nos muestra que es necesario una concienciación de que el cuerpo femenino se encuentra en nuestra sociedad de un modo muy afectado por convencionalismos patriarcales y que es necesaria una apropiación de dicho cuerpo por parte de la propia mujer y la abolición de estos imperativos. Para ello el concepto de la Gran Diosa es el espacio por excelencia en el que representar el cuerpo femenino desde una 
perspectiva femenina y en el que revisar dichos dogmas estéticos y plantear una crítica hacia el gran peso que estos tienen sobre las mujeres en la sociedad, las cuales se sienten oprimidas a encontrarse dentro de unos estándares de belleza cada vez más y más estrictos y que en ocasiones generan diferentes manifestaciones violentas contra su propia integridad física.

Esta necesidad de apropiación del cuerpo y de eliminación de las pautas agresivas que existen hacia él se encuentra paralela a la necesidad de erradicación de la violencia que se da hacia este género, una lacra existente en la actualidad a nivel global.

La violencia hacia el cuerpo de la mujer ha sido un tema que a lo largo de las últimas décadas ha ido cobrando más y más sensibilización ciudadana, contando con un aumento de las campañas de concienciación social y mayores herramientas para su control, sin embargo esta problemática continúa estando muy presente en todo el mundo, siendo muy sencillo toparnos con términos como abusos, violaciones, agresiones sexuales, acoso, violencia de género, o feminicidio en nuestro entorno a diario, un hecho que se encuentra en el punto de mira de muchas artistas del movimiento, influyendo su producción artística con el fin de hacerla visible y crear una conciencia colectiva de repulsa hacia las mismas. El papel de la divinidad femenina en este aspecto toma la necesidad de revisar el cuerpo de la mujer como sagrado, evitando con ello el rechazo por parte de miradas misóginas $\mathrm{y}$, por tanto, evitando también las diferentes manifestaciones violentas que le acompañan.

\section{UNA MIRADA HISTÓRICA}

En esta revisión sobre los abusos cometidos hacia la mujer se realiza también una crítica a la explotación que se ha dado en la Historia hacia los logros conseguidos por parte de mujeres, y por consiguiente la necesidad de una revalorización del papel tan importante que tuvieron en la Historia.

Nuestra Historia ha resultado ser una serie de acontecimientos en los que la figura de la mujer se ha encontrado ajena, en la que el papel protagonista ha sido siempre concedido al varón, dejando los éxitos de estas en un segundo plano. Por este motivo, la misión de sacar a la luz a aquellas mujeres clave en la Historia y que no se encuentran en ella por motivo de género, ha resultado una tarea que ha sido emprendida por muchas historiadoras y pensadoras durante décadas con el fin de concederles su valía y su lugar en la Historia, una búsqueda y reivindicación llevada a cabo también por el campo del arte. 


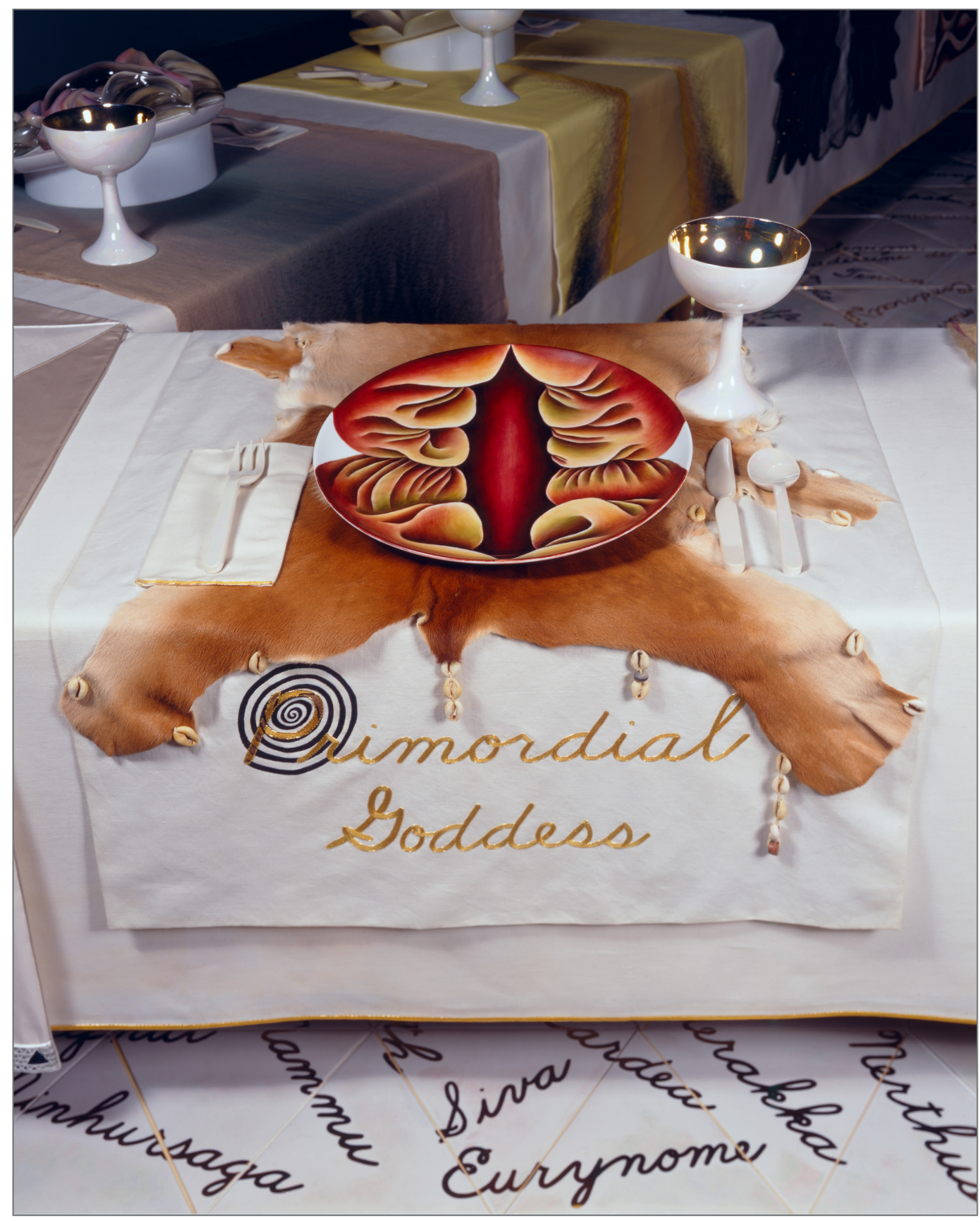

2. Primordial Goddess Place Setting in The Dinner Party. Judy Chicago. 1974-1979.

Remitiéndonos de nuevo al ejemplo de Judy Chicago, contamos con la obra The Dinner Party, en la que recuerda a aquellas mujeres cuyos logros han quedado silenciados por su condición de género y que a modo de invitación, realiza una reunión de todas ellas, criticando el anonimato al que se les ha 
confinado, así como una exaltación de su papel para la Historia. La Diosa supone una muestra de este rasgo histórico, ya que es ejemplo inequívoco de cómo el vestigio de una sociedad primigenia queda apartada por su estrecha relación con la mujer, y por tanto, su elección, la mejor estrategia a modo de crítica que expone cómo, desde antiguo, se lleva realizando este acto de ocultación.

\section{UNA CRÍTICA A LAS RELIGIONES PATRIARCALES Y UNA REVISIÓN CULTURAL}

Llegados a este punto, es imprescindible tratar el carácter religioso de la divinidad, el cual es innegable, suponiendo un claro y firme enfrentamiento a las religiones patriarcales.

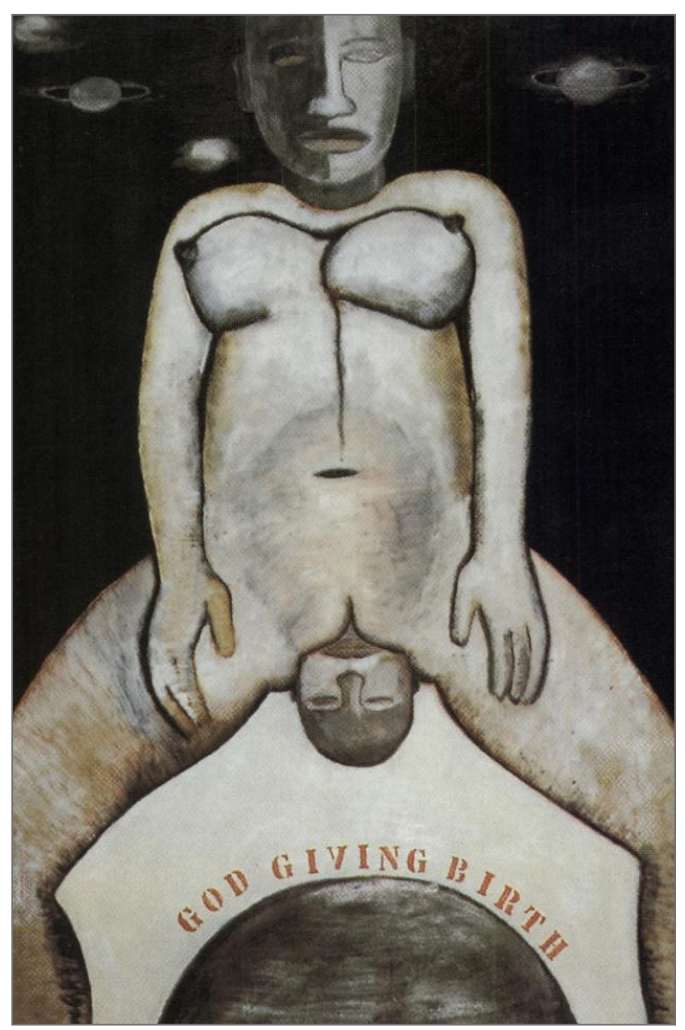

3 God Giving Birth. Monica Sjöö. 1968.
El hecho de encontrarnos ante una divinidad femenina es producto de una necesidad de reivindicar y rivalizar contra a la mayoría de las religiones imperantes en el mundo, la relación de oposición entre la Gran Diosa del feminismo y la religión cristiana es notable, ya que es la religión imperante en el momento y lugar en el que el movimiento cobra importancia.

La elección de una figura femenina como divina se contrapone al marcado carácter masculino que presentan las divinidades con más proyección a nivel mundial (judía - cristiana - musulmana) así como por las representaciones que encontramos de la divinidad, en el caso del cristianismo las cuales nunca han sido de corte femenino, pero sí como ente masculino ya que encontramos un ejemplo muy conocido en $L a$ creación de Adán, un fresco realizado por el artista Miguel Ángel Buonarroti en 1511 que decora la Capilla Sixtina, siendo una de las obras de arte más conocidas y reproducidas del mundo 
en contraposición al veto que obtuvo la obra God Giving Birth de Mónica Sjöö realizada en 1968 la cual estuvo censurada por años al representar a Dios como una madre dando a luz.

La gran represión que la iglesia ha perpetrado hacia la figura de la mujer a lo largo de la Historia y que continúa realizando a diferentes niveles en la actualidad, en la que no puede optar al mismo estatus y reconocimiento del varón y en la que proclama un modo de vida ligado a la falta de libertades, es un punto de mira hacia las reivindicaciones de esta imagen y tienen mucho que ver con el nacimiento de neopaganismos, así como un creciente movimiento espiritual femenino, ligado a los ciclos lunares, la naturaleza y el cuerpo de la mujer.

Por último cabría destacar el papel que juegan estas representaciones como una crítica de la cultura en sí, tomándola como uno de los factores que ejercen presión hacia la mujer y elaboran su modelo de conducta.

Sin duda alguna los seres humanos somos individuos sociales; necesitamos de la ayuda de otros para sobrevivir. La sociedad en la que nacemos nos construye como personas y rige una serie de pautas de actuación y conducta que nos hacen posible la convivencia con otros ciudadanos. Sin embargo, nuestras sociedades han dividido los modos de actuación, los modos en los que nos relacionamos y los modos en los que criamos a nuestros vástagos según nuestra condición biológica, dotando de una serie de características al género masculino que difieren de los del género femenino.

Esto ha sido un hecho a lo largo de la Historia, y son estas "leyes sociales no escritas", así como las políticas, las que construyen en mayor o menor medida, las pautas de actuación de una determinada población.

En algunos casos cabría apuntar que estos hechos, los patrones de conducta en cada sociedad, van muy estrechamente conectadas con la religión dominante, por tanto es difícil desdibujar las líneas de corte en las que es la sociedad o son las normas religiosas las que hacen al individuo.

Son por tanto varios aspectos los que influyen en gran medida a todas y cada una de las personas que integran una determinada sociedad y que da como resultado que, en varias ocasiones, la religión propiamente dicha sea más libre que la sociedad que la profesa. Una realidad que se conforma cuando el poder establecido, basándose en las normas religiosas, actúa de modo restrictivo hacia los propios individuos creando normas culturales, que secundadas por 
un pensamiento religioso, se tornan en comunes y válidas, pero plantean una realidad que va más allá de las pautas de actuación del pensamiento religioso.

Con todo ello y a modo de conclusión, es difícil delimitar con claridad todos los bloques de los que hemos hablado, a grandes rasgos, a lo largo de estas líneas, ya que todos ellos son parte de una totalidad, se complementan y ayudan a darse forma y sentido entre ellos, y no se podría hablar simplemente de uno, ya que se encuentran firmemente entrelazados y relacionados. La Gran Diosa del feminismo, es por tanto, la que a modo de metáfora nos plantea una visión amplia de los ideales de cambio del feminismo de segunda ola, así como nos ayuda a entender muchas de las obras que se realizaron con el auge del movimiento feminista de la época, y que se valen del cuerpo de la mujer, de mitos o de la propia imagen de la divinidad como elemento principal. Unas manifestaciones artísticas que comprenden un amplio abanico de disciplinas, pero que cuentan con un firme nexo de unión, la imagen de la divinidad, una imagen muy criticada y sin embargo muy desconocida, pero aun así, no olvidada.

\section{Referencias}

Fuss, Diana. 1999. En essència: feminisme, naturalesa i diferencia. Traducció d'Eva Espasa i Borràs. Vic: Eumo

Giedion, Sigfried. (1964) 1991. El presente eterno: Los comienzos del arte. Versión española de María Luisa Balseiro Madrid: Alianza

Gimbutas, Marija Alseikaite. (1984) 1991 Diosas y Dioses de la vieja Europa, 7000-3500 a.C. Presentación y revisión técnica, José María Gómez-Tabanera; traducción, Ana Parrondo. Madrid: Istmo

Gimbutas, Marija Alseikaite. 1989. The Language of the Goddess. London: Thames \& Hudson

Heresies Collective. 1978. "The Great Goddess". En: Heresies, vol. 5 Nueva York: Heresies Collective

Menéndez Requeno, Elena et al. 2015. La diosa en el espejo: Catálogo artístico : exposición colectiva. Sala Municipal de Exposiciones Centro Cultural de Mislata, 25 marzo -17 abril. Mislata: Ajuntament

Menéndez Requeno, Elena. 2013. "La magia del embarazo: Producción de cuatro series escultóricas de inspiración apotropaica". Trabajo fin de máster, Univ. Politécnica de València

Starhawk \& Donna Read. 2003. Signs out of time. New York: Alive Mind Media, DVD, 59 min.

Zohar, Ayelet et al. 2014. "Religion". Número monográfico N.paradoxa: International Feminist Art Journal 33. http://www.ktpress.co.uk/nparadoxa-volume-details.asp?volumeid=33

\footnotetext{
(Artículo recibido 29-04-17; aceptado 10-07-2017)
} 